\title{
Study of SMA-dowelled timber connection reinforced by densified veneer wood under cyclic loading
}

\author{
Haoyu Huang ${ }^{1, *}$, Wen-Shao Chang $^{2}$, Ke $\mathrm{Chen}^{3,4}$ \\ ${ }^{1}$ Beijing Key Lab of Earthquake Engineering and Structural Retrofit, the Key Laboratory of Urban Security and Disaster Engineering \\ of Ministry of Education, Beijing University of Technology, Beijing 100124, China \\ ${ }^{2}$ School of Architecture, University of Sheffield, Sheffield S10 2TN, UK \\ ${ }^{3}$ Department of Architecture and Civil Engineering, University of Bath, Bath BA2 7AY, UK \\ ${ }^{4}$ China Gezhouba Group Company Limited, Wuhan 430033, China
}

\begin{abstract}
This study explores the dynamic behaviours of shape memory alloy (SMA)-dowelled timber connection with densified veneer wood (DVW) reinforcement, so as to provide resilience to the timber structure. The performance of the SMA bar under cyclic bending is firstly studied, and it is found that it has superior self-centring effect and large ductility compared with that of the steel. By testing the SMAdowelled timber connections and the conventional steel-dowelled timber connections under cyclic loading at various displacement levels, it is shown that SMA can provide better self-centring effect and larger ductility to the connection. The DVW reinforcement can enhance the self-centring and improve the strength. However, the energy dissipation capacity of the SMA-dowelled timber connection is lower than that of the steel-dowelled connection because of the smaller hysteresis area of the SMA. In the further study, the effect of the temperature control on SMA should be investigated to improve the damping capacity of the SMAdowelled timber connection.
\end{abstract}

\section{Introduction}

Connections play an important role in the protection of the structure during the cyclic loadings. The strength of the connection ensures the stability of the structure and prevent the damage while the damping capacity of the connection can dissipate the energy during the cyclic loading and reduce the excessive deformation. Resilience is another significant requirement for the design of connections, because the large residual deformation could lead to the instability of the structure and can cause difficulties in the repair of the structure after earthquake and other disasters [1-3]. Therefore, it is of importance to design a resilience connection with satisfactory strength and damping capacity.

In timber engineering, dowel-type connection has been a common practice and been widely employed in the engineering. However, as indicated in the pilot study [1], the steel-dowelled timber connection has a large residual deformation after loading with a large displacement level, which is structurally harmful and also decreases the energy dissipation capacity. Our previous study adopted shape memory alloy (SMA) tubes into timber connections to provide seismic resilience [4]. SMA is a smart material with four phase transformation temperatures $M_{s}, M_{f}, A_{s}$ and $A_{f}$, which indicate the start and finish temperatures of the martensitic and austenitic transformations of SMA, respectively (as seen in Figure
1 (a)) [5]. When the in-service temperature is above $A_{f}$ SMA behaves in superelasticity (Figure 1 (b)), which provides a superior self-centring function, which facilitates the damping for seismic and wind-induced loadings. Due to the thermomechanical properties of SMA, the dynamic properties of SMAs are sensitive to changes in temperature [6]. The previous study [4] found the resilience of the timber connection can be improved a lot by applying SMA during the cyclic loading.

However, in the observation of our previous tests' results [4], bearing failure of timber is found to be a problem in timber connections. For all dowel-type connections, pinching effect of the hysteresis is common, and it is mainly caused by the elongation of timber due to the highly concentrated load at the hole. This phenomenon leads to non-recoverable embedment deformation, and splitting cracks may occur. Leijten [8] forwarded a concept that densified veneer wood (DVW) sheets can be incorporated in the timber connection reinforcing the dowel area, as DVW has high density of 1300$1400 \mathrm{~kg} / \mathrm{m}^{3}$ which can increase the embedment strength seriously. In comparison of steel sheets, the elasticity of DVW is lower thus it can reduce the stress concentration, moreover, DVW is easier for gluing [9]. More material descriptions of DVW can be found [10-12]. In Leijten [9]'s novel timber connection, the solid dowel is replaced by steel tube, which is expanded by hydraulic jack in order to achieving suitable clearance with timber.

* Corresponding author: huanghaoyu@ bjut.edu.cn 
Through this way, the stiffness of connection can be increased. When a smaller tube is expanded inside a bigger tube, namely, double tubes are used, the stiffness and strength can grow up [9]. Application of tube to dowel-type connection with DVW reinforcement will be a potential research direction. From the literature reviewed above, the strength of the timber connection could be increased and the timber embedment failure could be reduced by reinforcing DVW in the dowel area. Also, the residual deformation can be reduced since DVW can increase the embedment strength of the timber.

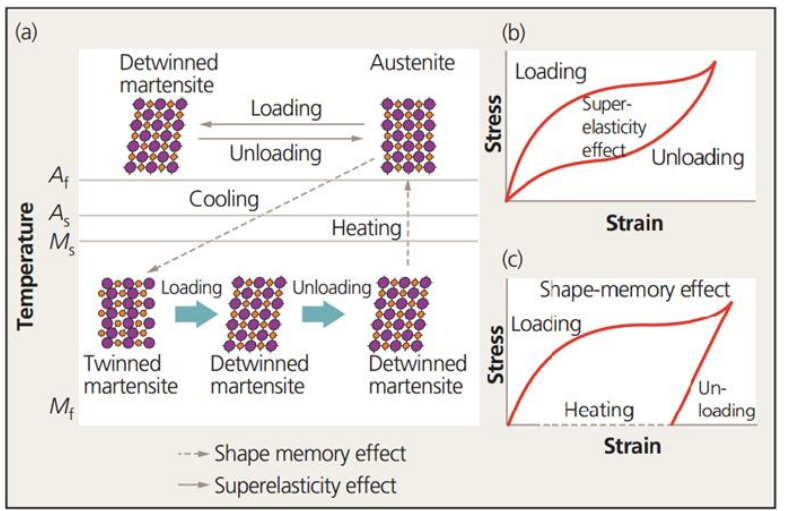

Fig. 1. (a) Different phases of SMAs at various temperatures and a stress-strain curve demonstrating the (b) superelasticity; (c) shape memory effect [7]

In this study, a novel SMA-dowelled connection with DVW is developed, in which SMA is used as the materials for dowels to present self-recoverable and energy-dissipating functions in the timber connection, and DVW prevents timber bearing failure. Both Copperbased SMAs and steel dowels are employed in the tests for comparison. Dynamic cyclic loadings with different displacement levels are carried out on double-shear timber connections. This study presents how this new dowel-type connection behaves and the effect of DVW and SMA on its dynamic performance.

\section{Material study of SMA}

\subsection{Methods}

Because SMA is applied as the dowel in timber connection for enhancing structural dynamic performance, the performance of the SMA bar under cyclic bending should be studied firstly in terms of the self-centring property, mechanical property, energy dissipation capacity and so on. However, the dynamic behaviours can vary depending upon different testing conditions and should be studied with specific regard to strain levels and specimens. Therefore, in relation the application, this study tests SMA bars with length of $125 \mathrm{~mm}$ and diameter of $12 \mathrm{~mm}$ under cyclic bending. The SMA utilising in this study is Cu-Al-Mn SMA provided by Shinko Metal Product Co., LTD, Japan. Araki et al. [13] and Huang [14] stated that Cu-Al-Mn SMA has a large recovery strain and fracture strain, and the low-cycle fatigue of $\mathrm{Cu}-\mathrm{Al}-\mathrm{Mn} \mathrm{SMA}$ was found to be superior. According to Araki et al. [15], copper-based SMA is less expensive than NiTi SMA, and the $\mathrm{Cu}-\mathrm{Al}-$ $\mathrm{Mn}$ alloy is the cheapest and even more inexpensive than other copper-based SMAs.

The element percentage of the SMA samples using in this study was analysed by scanning electron microscope, and was determined to be $\mathrm{Cu}=81.2 \%, \mathrm{Al}=7.8 \%$ and $\mathrm{Mn}=11.0 \%$ by weight. The transformation temperatures of this material were determined by DSC (Differential Scanning Calorimetry) with the result shown in Figure 2. The phase transformation temperatures are determined to be $M_{s}=-9^{\circ} \mathrm{C}, M_{f}=-25^{\circ} \mathrm{C}, A_{s}=-8^{\circ} \mathrm{C}$ and $A_{f}=5^{\circ} \mathrm{C}$. Thus, in the room temperature, the $\mathrm{Cu}-\mathrm{Al}-\mathrm{Mn}$ SMA behaves in superelasticity.

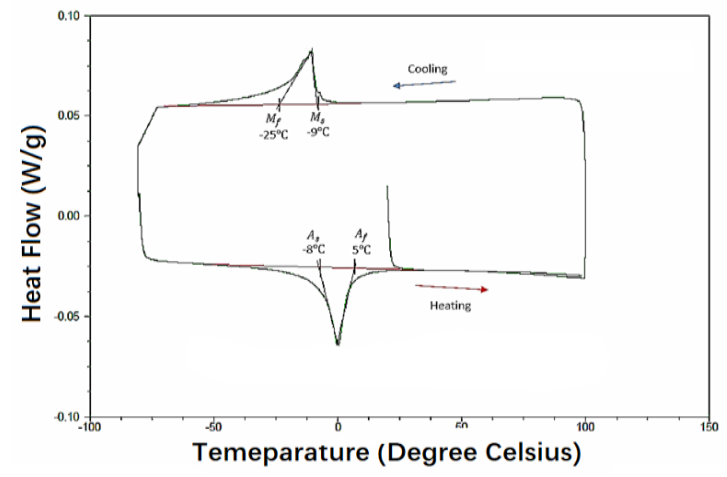

Fig. 2. DSC analysis of the SMA sample

The cyclic bending tests are conducted by a three-point bending rig as shown in Figure 3, the SMA bar was supported by two rounded bearings, and the bearings are free rotation. At the middle of the specimen bar, a steel plate was positioned so it could pull or push the SMA bar to a specified displacement, and six displacement levels of $2 \mathrm{~mm}, 4 \mathrm{~mm}, 6 \mathrm{~mm}, 8 \mathrm{~mm} 10 \mathrm{~mm}$ and $12 \mathrm{~mm}$ were selected. The loading frequency is $1 \mathrm{~Hz}$. At one displacement level, 10 cycles were repeated. During the test, the displacement and the force were recorded by the data logger. This testing in each condition was repeated by 5 SMA samples, and the same testing method was conducted on 5 steel bars as a comparison. The material for steel bars was mild steel graded EN3B (080A15) [16] and its yield stress was $310 \mathrm{MPa}$.

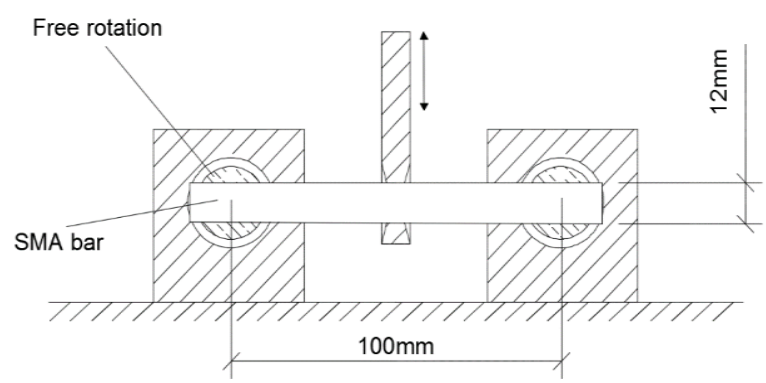

Fig. 3. Bending testing rig 


\subsection{Results and discussions}

The force-displacement relationships of one SMA bar and one steel bar are shown in Figure 4 and 5. It is notable that SMA bar has obvious self-centring behaviour from $2 \mathrm{~mm}$ displacement level to $12 \mathrm{~mm}$ displacement level in Figure 4. However, at the same displacement level, the steel bar undergoes nonlinear deformation and has large residual deformation. It is worth noted that the superelasticity of SMA is able to provide resilience property. According to the previous material studies on SMA [14], the strength decay and stiffness decay are common under cyclic loadings, while these decays are not observed in this study.

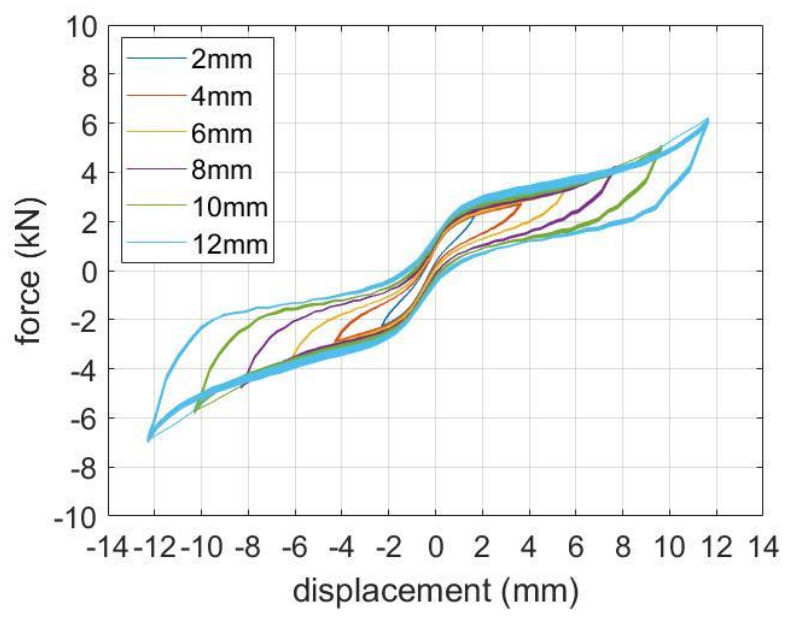

Fig. 4. Cyclic bending force-displacement relationship for SMA bar

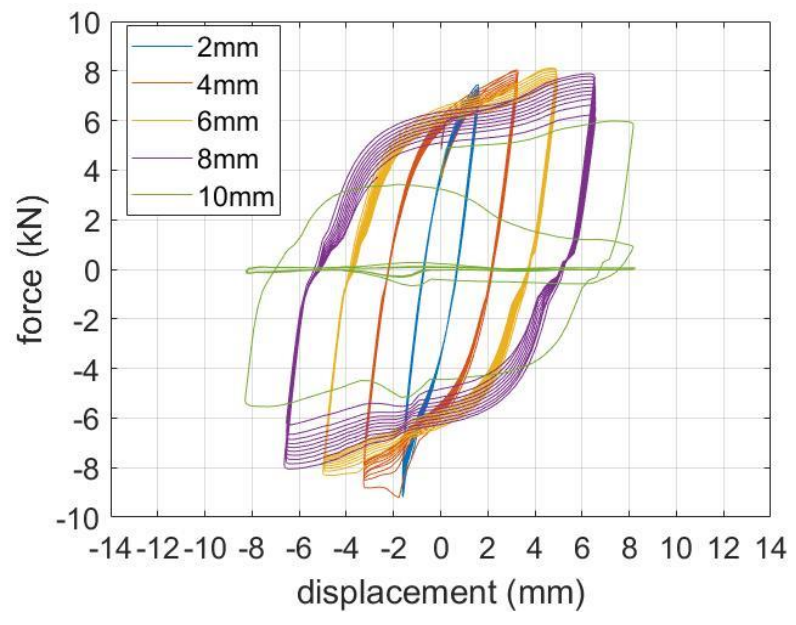

Fig. 5. Cyclic bending force-displacement relationship for steel bar

In Figure 6, the averaged strength of the 5 samples is calculated. At lower displacement level like $2 \mathrm{~mm}-8 \mathrm{~mm}$, the strength of SMA is lower than that of steel, but the difference is closing with the increase of the displacement level. At $10 \mathrm{~mm}$ displacement level, cracks developed on the steel bar and the strength dropped down dramatically, and then the steel bar is broken after one cycle as shown in Figure 5. In comparison, SMA bar presents much better low-cycle fatigue especially during the large displacement levels. It is also notable that the superelasticitic SMA has better ductility compared with steel as presented in Figures 4 and 5.

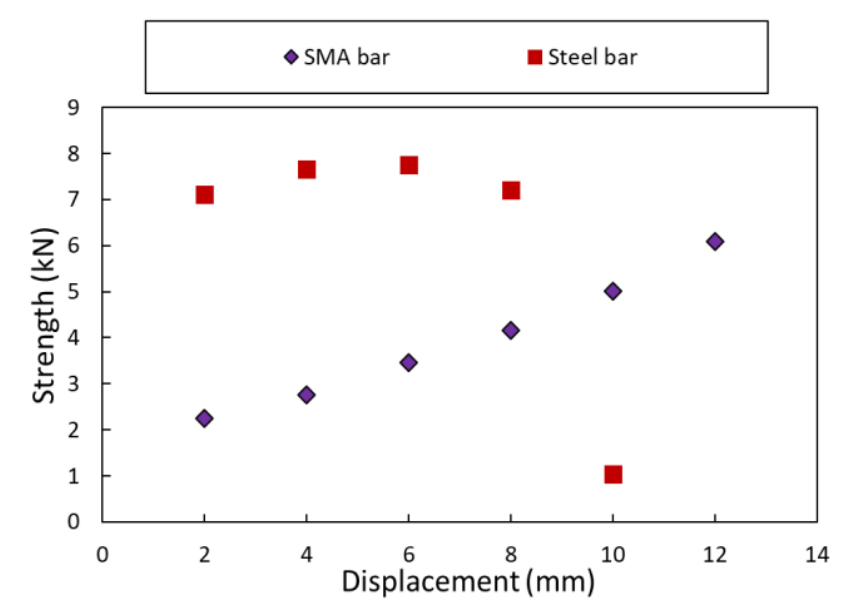

Fig. 6. Comparison of the averaged strength

\subsection{Summary}

By carrying out SMA material tests, it can be summarised that SMA has superior self-centring property, which has the potential to provide the resilience to the structural connection. SMA also has better ductility and fatigue compared with steel. The drawback of SMA is that its strength is lower than that of steel. All in all, SMA has the potential to be applied to the structural dynamic control.

\section{Testing of the timber connections}

\subsection{Materials and methods}

In this study, the tested timber connection is a doubleshear connection with one dowel. The timber used is swan softwood graded C24 and the species is spruce. By following the standard EN383 [17], the characteristic embedment strength paralleled to strain is $18.95 \mathrm{Mpa}$, and the averaged moisture content and characteristic density were $11.3 \%$ and $306.78 \mathrm{~kg} / \mathrm{m}^{3}$, respectively. The experimental timber connection is shown in Figure 7, and the dimensions are labelled on the picture. On the dowel area, the DVW sheets with the dimensions of 100 $\times 120 \times 12 \mathrm{~mm}$ are glued using epoxy at the two sides of the timber sheets as presented in Figure 7, which is a reinforcement for the dowel area. The DVW is provided by ROCHLING Engineering Plastics graded C4R. 


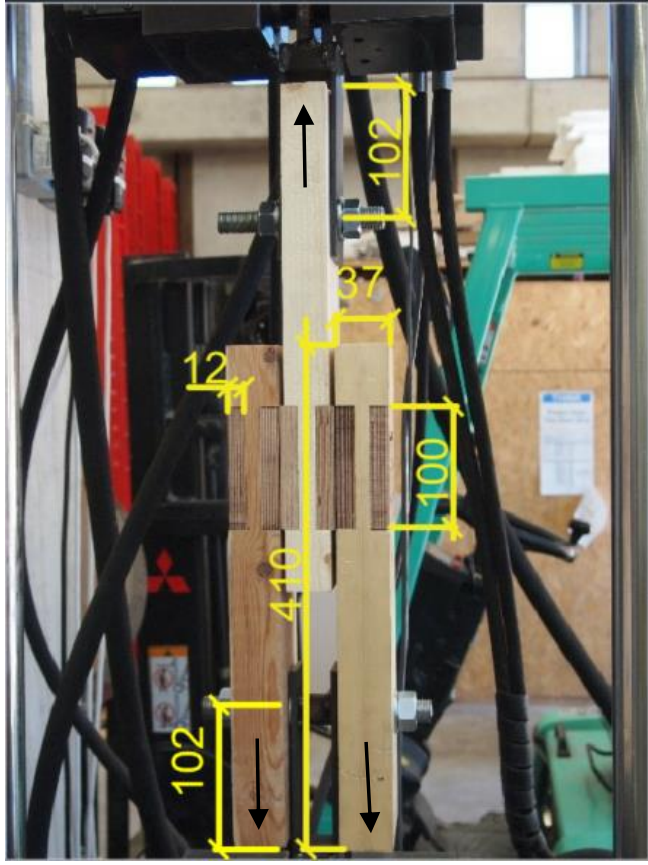

(a)

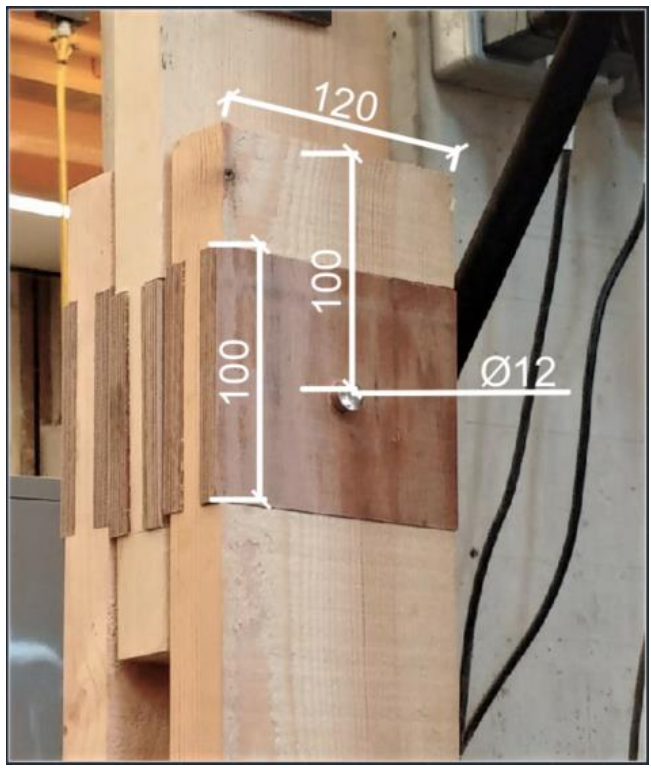

(b)

Fig. 7. (a) Test setup of double-shear SMA-dowelled timber connection; (b) DVW reinforcement

There are two types of timber connections tested in this study; one is SMA-dowelled timber connection and another type is steel-dowelled timber connection as a comparison. The SMA and steel dowels used in the timber connections are same with those used in the material tests, and they are bars with length of $125 \mathrm{~mm}$ and diameter of $12 \mathrm{~mm}$. The test set-up is presented in Figure 7. The experimental timber connection belongs to a double-shear model, and it is tested by giving a cyclic tension-compression loads as shown in Figure 7 (a). The timber is connected to the loading machine using a steel clamp, and the distance between the connecting hole and the boundary is $102 \mathrm{~mm}$.
The testing protocol is same with that used in the previous study [4]. The connection is tested at 4 displacement levels of 2, 4, 6 and $8 \mathrm{~mm}$ at a loading frequency of $1 \mathrm{~Hz}$, and there are 10 loading cycles at each displacement level. The detailed loading scheme is presented in Figure 8. During the tests, the load is measured by the load cell of the loading machine, and the displacement is measured by the operating stroke of the loading machine with a sampling rate of $100 \mathrm{~Hz}$. In each testing condition, 5 samples are repeated.

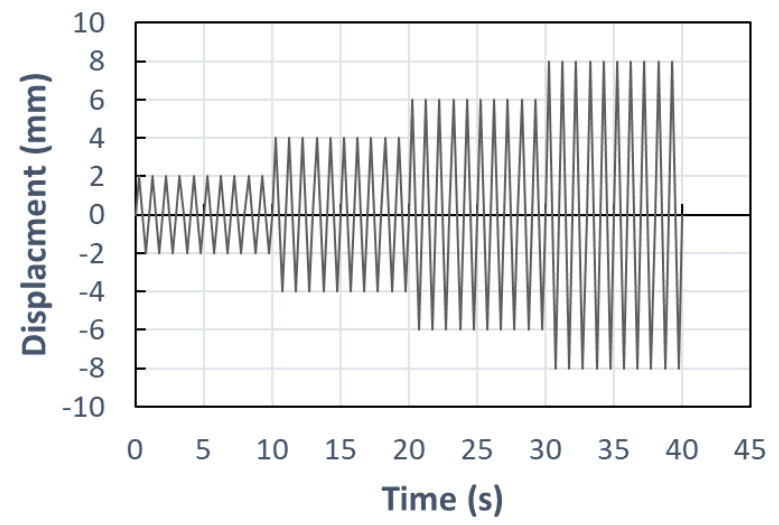

Fig. 8. Loading scheme

\subsection{Results and discussions}

\subsubsection{Failure mode}

By observing the failure mode, the embedment failure is rare in all tested samples, because DVW can enhance the strength of the timber bearing area for the dowel. The deformation is mainly from the bending of the SMA/steel dowel. In double-shear timber connection, the deformation of the dowel resembles a three-point bending, thus a plastic hinge usually occurs in the middle of the dowel. After the cyclic loading, no SMA dowel is broken, but 4 steel dowels are fractured at the middle part when the displacement is at $8 \mathrm{~mm}$. This result shows SMA-dowelled connections have longer low-cycle fatigue life.

\subsubsection{Self-centring behaviour}

In Figure 9, the force-displacement curves $\left(10^{\text {th }}\right.$ cycle $)$ of one test of SMA-dowelled connections and one test of steel-dowelled connection are compared. It can be found that the residual displacement of SMA-dowelled connection is much smaller than that of steel-dowelled connection, which shows a satisfactory self-cantering property. For instance, at $8 \mathrm{~mm}$ displacement level, the residual displacement at $10^{\text {th }}$ cycle of SMA-dowelled connection is $5.6 \mathrm{~mm}$ while that of steel-dowelled connection is $2.4 \mathrm{~mm}$. 


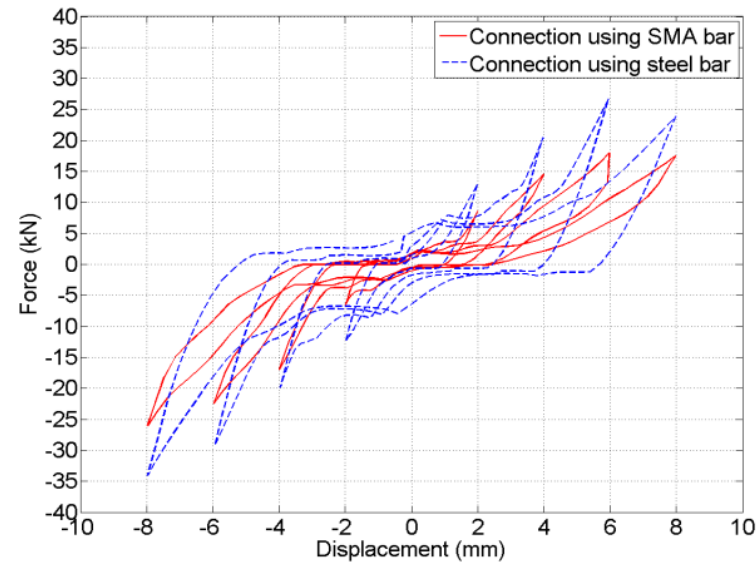

Fig. 9. Force-displacement relationship of SMA-dowelled and steel-dowelled connections reinforced by DVW $\left(10^{\text {th }}\right.$ cycle $)$

By comparing with the tests results of the timber connections without DVW reinforcement in our previous study [4] as shown in Figure 10, it can be found the selfcentring property is improved by reinforcing DVW. For example, by applying DVW, the residual displacements of the $10^{\text {th }}$ cycle at $8 \mathrm{~mm}$ displacement level are reduced by $46.7 \%$ in SMA-dowelled connection and $9.6 \%$ in steel-dowelled connection. The reason could be explained that the bearing failure of timber at dowel area is resisted and thus the residual deformation from the timber is reduced.

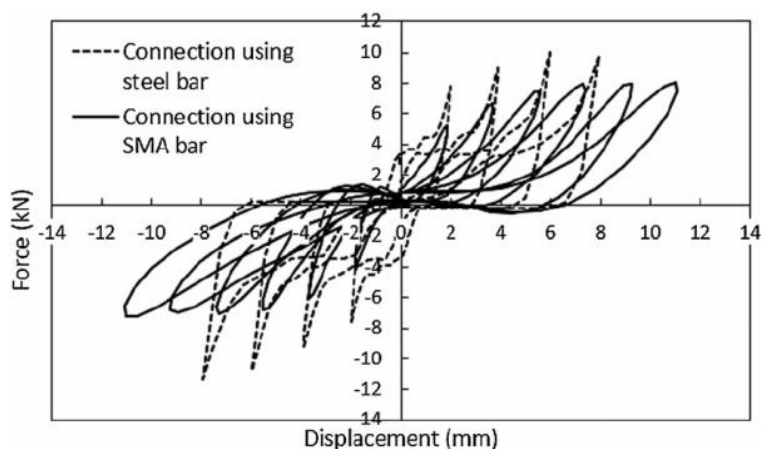

Fig. 10. Force-displacement relationship of SMA-dowelled and steel-dowelled connections without DVW reinforcement $\left(10^{\text {th }}\right.$ cycle) (Previous results conducted by Huang and Chang in 2017 [4])

\subsubsection{Stiffness and strength}

The initial stiffness the SMA-dowelled timber connection shown in Figure 9 is $4.044 \mathrm{kN} / \mathrm{mm}$ while the stiffness of the steel-dowelled timber connection is $6.475 \mathrm{kN} / \mathrm{mm}$. It is found that the stiffness of the steeldowelled connection is higher than that of the SMAdoweled connection. In Figure 11, the strength at the $10^{\text {th }}$ cycle of SMA and steel-dowelled timber connections with and without DVW reinforcement are compared. The data of the connections without DVW reinforcement are from the previous study [4]. It is obvious that the steel-dowelled timber connections have larger strength than that of the SMA-dowelled connections no matter whether the DVW reinforcement is applied or not. This is owing to the strength of steel is higher than that of SMA. By employing the DVW, the strength of the connection can be greatly improved. For instance, the strength of the SMA-dowelled connection at $10^{\text {th }}$ cycle at $8 \mathrm{~mm}$ displacement level can be raised about 2.3 times by applying DVW.

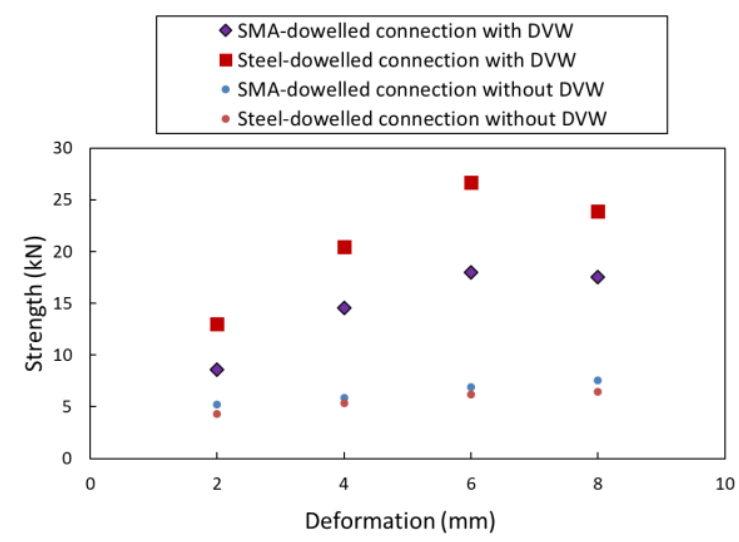

Fig. 11. Strength of the SMA-dowelled and steel-dowelled timber connection with and without DVW at $10^{\text {th }}$ cycle (data of connections without DVW are from [4])

\subsubsection{Energy dissipation capacity}

Equivalent viscous damping ratio (EVDR) is an important indicator to evaluate the energy dissipation of the timber connection. In this study, the EVDR is calculated based on the methods in BS EN12512 [18]. Figure 12 compares the EVDR at $10^{\text {th }}$ cycle of SMA and steel-dowelled timber connections with and without DVW reinforcement. It indicates that the EVDR of the steel-dowelled timber connection is higher than that of SMA-dowelled timber connection. Because of selfcentring, the hysteresis area of SMA shrinks by contrast of that of steel according to Figures 4 and 5. The difference becomes more obvious when the deformation is larger. By applying DVW, the energy dissipation of SMA-dowelled connection becomes less. This can be owing to that the better self-centring is the less EVDR is. To increase the damping of SMA, one way is to decrease the in-service temperature of SMA, because the SMA phase approaches the martensitic phase and it is more like a shape memory effect with the decrease of temperature. In the future research, a cooling technique can be investigated to lower the in-service temperature of the SMA dowel that the damping capacity can be improved. 


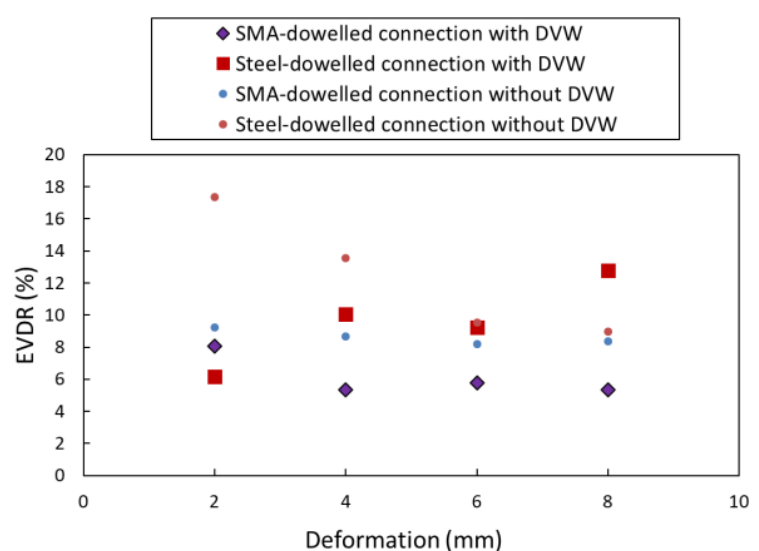

Fig. 12. EVDR of the SMA-dowelled and steel-dowelled timber connection with and without DVW at $10^{\text {th }}$ cycle (data of connections without DVW are from [4])

\section{Conclusion}

To provide the resilience to the timber connection under the dynamic effect, a SMA-dowelled timber connection with DVW reinforcement is raised, tested and compared with the conventional steel-dowelled timber connection. The dynamic behaviours of the SMA is firstly studied under cyclic bending at displacement levels from $2 \mathrm{~mm}$ to $12 \mathrm{~mm}$. The testing results present SMA provides a superior self-centring behaviour and a large ductility. Even though the strength of SMA is lower than that of the steel, SMA shows a potential to be used in the structural control. This study tested the SMA-dowelled and steel-dowelled timber connections reinforced by DVW under cyclic loadings at different amplitudes. The testing results show the residual deformation of SMAdowelled connection is much lower than that of steeldowelled connection, and the SMA-dowelled connection has better ductility. The DVW reinforcement can greatly improve the self-centring effect, and increase the strength both in steel and SMA-dowelled connections. The energy dissipation of the SMA-dowelled timber connection is lower than that of steel-dowelled connection, because the self-centring shrinks the hysteresis area. In the further study, a temperature control technique on the SMA should be investigated to rise the damping ratio of the connections.

\section{Acknowledgement}

The authors would like to thank the Start-up Funds for New Lecturers with Doctorates at Beijing University of Technology, Basic Research Foundation of Beijing University of Technology and International Copper Association (TEK-1079) for their supports. The authors also thank Shinko Metal Product Co., LTD for their shape memory alloy supply.

\section{References}

[1] Chang WS, Murakami S, Komatsu K, Araki Y, Shrestha K, Omori T et al. Technical Note: Potential to
Use Shape Memory Alloy in Timber Dowel-Type Connections. Wood Fiber Sci. 2013;45:330-4.

[2] Ma HW, Wilkinson T, Cho CD. Feasibility study on a self-centering beam-to-column connection by using the superelastic behavior of SMAs. Smart Materials \& Structures. 2007;16:1555-63.

[3] Youssef MA, Alam MS, Nehdi M. Experimental investigation on the seismic behavior of beam-column joints reinforced with Superelastic Shape Memory Alloys. J Earthq Eng. 2008;12:1205-22.

[4] Huang HY, Chang WS. Seismic resilience timber connectionadoption of shape memory alloy tubes as dowels. Struct Control Hlth. 2017;24.

[5] Desroches R, Smith B. Shape memory alloys in seismic resistant design and retrofit: A critical review of their potential and limitations. J Earthq Eng. 2004;8:41529.

[6] Shaw JA, Kyriakides S. Thermomechanical aspects of NiTi. J Mech Phys Solids. 1995;43:1243-81.

[7] Chang W-S, Araki Y. Use of shape memory alloy in construction: A critical review. Proceedings of the ICE Civil Engineering. 2016.

[8] Leijten AJM. Development of reinforced joints with densified veneer wood. Proc, 1991 Int Timber Engineering Conf1991. p. 36-42.

[9] Leijten AJM. The concept of the prestressed DVW reinforced joint with expanded tubes. Proceedings of the international wood engineering conference1996. p. 2959.

[10] Kollmann FFP, Côté WA. Principles of wood science and technology. Berlin, Heidelberg, New York, Springer-Verlag; 1968.

[11] Guan ZW, Rodd P. DVW - Local reinforcement for timber joints. J Struct Eng-Asce. 2001;127:894-900.

[12] Leijten AJM, Ruxton S, Prion H, Lam F. Reversedcyclic behavior of a novel heavy timber tube connection. J Struct Eng-Asce. 2006;132:1314-9.

[13] Araki Y, Maekawa N, Omori T, Sutou Y, Kainuma $\mathrm{R}$, Ishida $\mathrm{K}$. Rate-dependent response of superelastic $\mathrm{Cu}$ Al-Mn alloy rods to tensile cyclic loads. Smart Materials and Structures. 2012;21.

[14] Huang H. A Temperature Controlled Semi-active Tuned Mass Damper using Shape Memory Alloy for Vibration Reduction Applications. Bath, UK: University of Bath; 2017.

[15] Araki Y, Endo T, Omori T, Sutou Y, Koetaka Y, Kainuma $\mathrm{R}$ et al. Potential of superelastic $\mathrm{Cu}-\mathrm{Al}-\mathrm{Mn}$ alloy bars for seismic applications. Earthquake Eng Struc. 2011;40:107-15.

[16] Institution BS. BS 970-1:1996 - Specification for wrought steels for mechanical and allied engineering purposes. General inspection and testing procedures and specific requirements for carbon, carbon manganese, alloy and stainless steels. 1996.

[17] Institution BS. BS EN 383:2007 -Timber structures - Test methods - Determination of embedment strength and foundation values for dowel type fasteners. 2007.

[18] Institution BS. Bs En 12512:2001 - Timber structures - Test methods - Cyclic testing of joints made with mechanical fasteners. 2001. 